\section{OPEN ACCESS}

Edited by:

Hollie Marie Reeves,

University Hospitals Cleveland Medical

Center, United States

Reviewed by:

Long-Sheng Lu,

Taipei Medical University, Taiwan

Roberto Carnevale,

Sapienza University of Rome, Italy

*Correspondence:

Marina Noris

marina.noris@marionegri.it

Specialty section:

This article was submitted to

Hematology,

a section of the journal

Frontiers in Medicine

Received: 02 July 2020 Accepted: 30 September 2020 Published: 03 November 2020

Citation:

Piras R, latropoulos $P$, Bresin $E$, Todeschini M, Gastoldi S, Valoti E,

Alberti M, Mele C, Galbusera M

Cuccarolo P, Benigni A, Remuzzi G and Noris M (2020) Molecular Studies and an ex vivo Complement Assay on

Endothelium Highlight the Genetic

Complexity of Atypical Hemolytic

Uremic Syndrome: The Case of a

Pedigree With a Null CD46 Variant.

Front. Med. 7:579418.

doi: 10.3389/fmed.2020.579418

\title{
Molecular Studies and an ex vivo Complement Assay on Endothelium Highlight the Genetic Complexity of Atypical Hemolytic Uremic Syndrome: The Case of a Pedigree With a Null CD46 Variant
}

\section{Rossella Piras, Paraskevas latropoulos, Elena Bresin, Marta Todeschini, Sara Gastoldi, Elisabetta Valoti, Marta Alberti, Caterina Mele, Miriam Galbusera, Paola Cuccarolo, Ariela Benigni, Giuseppe Remuzzi and Marina Noris*}

Clinical Research Center for Rare Diseases 'Aldo e Cele Daccò, 'Istituto di Ricerche Farmacologiche Mario Negri IRCCS, Bergamo, Italy

Atypical hemolytic uremic syndrome (aHUS) is an ultra-rare disease characterized by microangiopathic hemolysis, thrombocytopenia, and renal impairment and is associated with dysregulation of the alternative complement pathway on the microvascular endothelium. Outcomes have improved greatly with pharmacologic complement C5 blockade. Abnormalities in complement genes (CFH, CD46, CFI, CFB, C3, and THBD), $\mathrm{CFH}-\mathrm{CFHR}$ genomic rearrangements, and anti-FH antibodies have been reported in $40-60 \%$ of cases. The penetrance of aHUS is incomplete in carriers of complement gene abnormalities; and multiple hits, including the $\mathrm{CFH}-\mathrm{H} 3$ and $\mathrm{CD} 46_{\mathrm{GGAAC}}$ risk haplotypes and the $C F H R 1^{*} B$ risk allele, as well as environmental factors, contribute to disease development. Here, we investigated the determinants of penetrance of aHUS associated with CD46 genetic abnormalities. We studied 485 aHUS patients and found CD46 rare variants (RVs) in about $10 \%$. The c.286+2T>G RV was the most prevalent (13/485) and was associated with $<30 \%$ penetrance. We conducted an in-depth study of a large pedigree including a proband who is heterozygous for the c.286+2T>G RV who experienced a severe form of aHUS and developed end-stage renal failure. The father and paternal uncle with the same variant in homozygosity and six heterozygous relatives are unaffected. Flow cytometry analysis showed about 50\% reduction of CD46 expression on blood mononuclear cells from the heterozygous proband and over 90\% reduction in cells from the proband's unaffected homozygous father and aunt. Further genetic studies did not reveal RVs in known aHUS-associated genes or common genetic modifiers that segregated with the disease. Importantly, a specific ex vivo test showed excessive complement deposition on endothelial cells exposed to sera from the proband, and also from his mother and maternal uncle, who do not carry the c.286+2T>G RV, indicating that they share a circulating defect that results in complement dysregulation on the endothelium. These results highlight the complexity of the genetics of aHUS and indicate that 
CD46 deficiency may not be enough to induce aHUS. We hypothesize that the proband inherited from his mother a genetic abnormality in a complement circulating factor that has not been identified yet, which synergized with the CD46 RV in predisposing him to the aHUS phenotype.

Keywords: atypical hemolytic uremic syndrome, complement, membrane cofactor protein, incomplete penetrance, splicing, CD46 expression, ex-vivo assay, rare variants

\section{INTRODUCTION}

Hemolytic uremic syndrome (HUS) is an ultra-rare disease characterized by microangiopathic hemolytic anemia, thrombocytopenia, and renal impairment (1) caused by platelet thrombi in the microcirculation of the kidney and other organs. Atypical HUS (aHUS) accounts for about $10 \%$ of all cases and has a poor prognosis compared with the most common form of HUS in children, which is caused by Shiga-like toxin producing Escherichia coli (STEC) (1). Before the introduction of C5 inhibition therapy, up to 50\% of aHUS cases progressed to end-stage renal failure (ESRF) or developed irreversible brain damage, and $25 \%$ died during the acute phase of the disease $(2,3)$.

The term primary aHUS identifies cases characterized by dysregulation of the alternative complement pathway $(2,4)$. Rare recessive forms of aHUS are associated with genetically determined cobalamin C (5) or diacylglycerol kinase 3 deficiency $(6,7)$. Finally, aHUS may be secondary to other conditions, such as autoimmune diseases, systemic diseases, malignant hypertension, and transplantation $(4,8)$.

In $40-60 \%$ of patients with primary aHUS, genetic abnormalities affecting the complement regulatory proteins factor $\mathrm{H}(C F H)$, membrane cofactor protein $(M C P)$, factor I $(C F I)$, and thrombomodulin (THBD) and the components of the alternative pathway $\mathrm{C} 3$ convertase $\mathrm{C} 3$ and factor $\mathrm{B}(C F B)$ or anti-FH autoantibodies have been identified (2, 9-13). Less than $20 \%$ of cases are considered familial, that is, cases where two or more members of the same family are affected by the disease and exposure to STEC has been ruled out. All the other patients do not have a family history of the disease (sporadic aHUS), and most of them inherited the complement abnormality from an unaffected parent. Indeed, incomplete penetrance has been reported for all genes associated with aHUS. Other genetic modifiers, including risk haplotypes and polymorphisms and environmental factors have been shown to contribute to the development of disease phenotypes (14-16). A wide variety of triggers have been identified, including common viral and bacterial infections, ischemia, organ transplantation, and pregnancy.

Mutations in the gene encoding membrane cofactor protein (also known as CD46), first described in association with aHUS in $2003(17,18)$, account for 5 to $9 \%$ of cases with primary aHUS. MCP is a transmembrane protein made by four N-terminal short consensus repeats (SCRs), a serine/threonine-rich (ST) domain, a transmembrane domain (TM), and a cytoplasmic tail (CYT) and serves as cofactor for factor I (FI), a plasma serine protease that cleaves $\mathrm{C} 3 \mathrm{~b}$ and $\mathrm{C} 4 \mathrm{~b}$. It is widely expressed on all nucleated cells and is particularly highly expressed in the kidney (19), where it regulates $\mathrm{C} 3$ activation in the glomerulus.

aHUS-associated CD46 variants usually cluster in the extracellular complement regulatory SCR domains (14, 20-22). Seventy-five percent cause a reduction in MCP expression on the cell surface $(23,24)$.

The penetrance of aHUS among subjects with CD46 mutations is incomplete, and $25 \%$ of patients had combined mutations in other complement genes (12).

Here, we investigated the determinants of CD46 mutation penetrance. We found that the splicing variant c. $286+2 \mathrm{~T}>\mathrm{G}$ (also known as IVS2+2T>G; dbSNP: rs769742294) is the most prevalent $C D 46$ genetic abnormality in our cohort of patients $(n=485)$ with primary aHUS, and within families, disease penetrance in c. $286+2 \mathrm{~T}>\mathrm{G}$ carriers was $28 \%$. We performed an in-depth study of the large pedigree of a patient with sporadic aHUS who is heterozygous for this variant. Fremeaux-Bacchi et al. demonstrated that this splice-site variant results in abnormal splicing, causing a deletion of 48 amino acids in the SCR1 of the protein (24). Afterwards, Maga et al. reported that the c. $286+2 \mathrm{~T}>\mathrm{G}$ results in another abnormally spliced mRNA, leading to a frameshift and the translation of a truncated protein (p.Glu97Lysfs*33) (25).

In published studies, the $c .286+2 \mathrm{~T}>\mathrm{G}$ variant was associated with a variable phenotype: heterozygous carriers have a milder form of aHUS, while the disease is more severe and has an earlier onset in homozygous carriers $(24,26)$. In contrast, in our pedigree, the heterozygous proband manifested a severe form of aHUS and developed ESRF, while two adult relatives (his father and paternal uncle) with the same variant in homozygosity are unaffected. Screening for other known aHUS-associated complement genes did not reveal rare or common variants that segregated with the disease. An ex vivo test showed excessive complement deposition on endothelial cells exposed to sera from the proband, and also from his mother and his maternal uncle, who do not carry the c. $286+2 \mathrm{~T}>\mathrm{G}$ variant, indicating that the proband inherited a maternal circulating defect in complement regulation. These results highlight the complexity of the genetics of aHUS and indicate that CD46 deficiency may not be not enough to cause aHUS.

\section{MATERIALS AND METHODS}

\section{Study Subjects}

Four hundred eighty-five unrelated patients with a diagnosis of primary aHUS were recruited through the International Registry of HUS/TTP, under the coordination of the Aldo and 
Cele Daccò Clinical Research Center for Rare Diseases (Ranica, Bergamo, Italy).

Clinical information and demographic and laboratory data for all patients and their available relatives were collected using a case report form. Biochemical and genetic tests were performed on blood, plasma, serum, and DNA samples collected from all aHUS patients and available relatives.

All participants received detailed information on the purpose and design of the study, according to the guidelines of the Declaration of Helsinki.

aHUS was diagnosed in all cases with microangiopathic hemolytic anemia and thrombocytopenia [defined as hematocrit (Ht) $<30 \%$, hemoglobin $(\mathrm{Hb})<10 \mathrm{~g} / \mathrm{dl}$, serum lactate dehydrogenase $(\mathrm{LDH})$ of $>500 \mathrm{IU} / \mathrm{L}$, undetectable haptoglobin, fragmented erythrocytes in the peripheral blood smear, and platelet count less of than $150,000 / \mu \mathrm{l}$ ] associated with acute renal failure (serum creatinine $>1.3 \mathrm{mg} / \mathrm{dl}$ for adults, $>0.5 \mathrm{mg} / \mathrm{dl}$ for children under 5 years old and $>0.8 \mathrm{mg} / \mathrm{dl}$ for children aged $5-10$, and/or urinary protein-creatinine ratio $>200 \mathrm{mg} / \mathrm{g}$; or an increase in serum creatinine or urinary protein-creatinine ratio $>15 \%$ compared with baseline levels). Thrombotic thrombocytopenic purpura was ruled out because all patients exhibited ADAMTS13 activity $>10 \%$ and no anti-ADAMTS13 antibodies. Primary aHUS was defined in aHUS patients when both secondary underlying conditions and infections by Stx-E.coli were ruled out.

Ethnically matched healthy controls $(n=319)$ were also recruited from blood donors and were screened for CD46 variants that we found in primary aHUS patients.

All participants provided informed written consent. The study protocol was approved by the Ethics Committee of the Azienda Sanitaria Locale, Bergamo, Italy.

\section{Genetic Screening and Biochemical Testing}

Genomic DNA was extracted from peripheral blood leukocytes (Nucleon BACC2 kit, Amersham; NucleoSpin Blood kit, Macherey-Nagel). All coding exons and the intronic flanking regions of membrane cofactor protein (CD46), complement factor $\mathrm{H},(\mathrm{CFH})$, complement factor I $(C F I)$, complement factor $\mathrm{B}(\mathrm{CFB})$, complement $\mathrm{C} 3(\mathrm{C} 3)$, and thrombomodulin $(\mathrm{THBD})$ genes were amplified by polymerase chain reaction (PCR), using gene-specific primers and standard conditions. Amplification products were sequenced using standard Big-Dye Terminator v.1.1 protocols on 48-capillary 3730 DNA Analyzer. Sixty patients who were recruited more recently were analyzed using a homemade next-generation sequencing (NGS) diagnostic mini panel for simultaneous sequencing of the six complement genes reported above using a combination of multiplex PCR and highthroughput sequencing (PGM Ion Torrent, Life technologies). dbSNP, 1,000 genomes, ESP6500, and ExAC databases were used to distinguish new variants from those that had already reported. Ethnically matched healthy controls $(n=319)$ were screened for rare CD46 variants found in non-Stx-HUS patients.

Genetic variants with a reported minor allelic frequency (MAF) below 0.001 in 1,000 Genomes and in the Exome
Aggregation Consortium (ExAC), not found in 319 healthy controls and with a Combined Annotation Dependent Depletion (CADD) phred score $\geq 10$ were considered rare variants (RVs). CD46 RVs were further classified in "pathogenic," "likely pathogenic," "uncertain significance," "likely benign," or "benign" using the guidelines from the American College of Medical Genetics and Genomics (ACMG) (27) and Kidney Disease: Improving Global Outcomes (KDIGO) conference (4).

Once a RV was identified, the parents and relatives of the proband were invited for genetic testing to study the transmission model.

In patients carrying the CD46 c. $286+2 \mathrm{~T}>\mathrm{G}$ RV and their available relatives, we genotyped by direct sequencing the CFH single-nucleotide polymorphisms (SNPs) (c.1-331C > T, rs3753394; c.184G >A, p.V62I, rs800292; c.1204C>T, p.H402Y, rs1061170; c.2016A>G, p.Q672Q, rs3753396; c.2237-543G>A, rs1410996; c.2808G $>$ T, p.E936D, rs1065489) that define the disease risk haplotype $\mathrm{CFH}_{T G T G G T}$ (known as $\mathrm{CFH}-\mathrm{H3}$ haplotype) and one SNP in CD46 (rs7144, c.*897T>C) that tags the risk $C D 46_{G G A A C}$ haplotype.

All CFHR5 exons and the three nucleotide differences in exon 4 of CFHR1 (c.469, c.475, and c.523) that distinguish the $C F H R 1^{*} A$ and $C F H R 1^{*} B$ alleles were also genotyped in the proband and his relatives, using direct sequencing. The three differences cause three amino acid changes in SCR3 of FHR1 that make SCR3 of FHR1 identical to SCR18 of FH (28). The SCR3 with Tyr157, Val159, and Gln175 amino acids characterizes the basic isoform of FHR1 and is identical to the SCR18 of FH, indicating that the $C F H R 1^{*} B$ allele could be the result of a gene conversion between $C F H$ and $C F H R 1$. The $C F H R 1^{*} B$ allele has been found to be associated with aHUS patients carrying the homozygous $C F H R 1^{*} B$ allele.

Multiplex ligation-dependent probe amplification (SALSA MLPA P236-A3 ARMD, MCR-Holland) was used to evaluate copy number variations in $C F H, C F H R 3, C F H R 1, C F H R 2$, and CFHR5 genes.

The mRNA extracted from peripheral blood mononuclear cells (PBMCs) from the proband and his relatives in family \#646 was reverse transcripted using SuperScript ${ }^{\circledR}$ II Reverse Transcriptase (Invitrogen, Carlsbad, CA, United States). cDNA amplification and sequencing were performed using a forward primer constructed on exon 1 (signal peptide) (5'-GCTTTCCTGGGTTGCTTCT) and a reverse primer constructed on exon 3 (SCR2) (5'-CATTTGCAGGGACTGCTTG).

Complement C3 and C4 serum levels were evaluated using kinetic nephelometry (14). Plasma SC5b-9 levels were evaluated with the MicroVue SC5b-9 Plus EIA commercial kit (SC5b-9 Plus, Quidel). The presence of anti-FH antibodies was evaluated using enzyme-linked immunosorbent assay (ELISA) (13).

\section{CD46 Expression Studies on Peripheral Blood Mononuclear Cells}

PBMCs were isolated from the peripheral blood of the proband, his relatives, and healthy volunteers by performing density gradient centrifugation using Ficoll-Paque. Fresh or thawed 
PBMCs were labeled with anti-human CD3 APC-Cy7 or alternatively anti-human CD3 BV510 (clone SK7) and with antibody anti-human CD46 fluorescein isothiocyanate (FITC) (clone E4.3 that recognizes SCR1 epitope) or with antibody anti-human CD46 FITC (clone MEM258 that recognizes SCR4 epitope). Each experiment was performed using PBMCs from healthy volunteers labeled for $\mathrm{CD} 3$ and $\mathrm{CD} 46$ (SCR1) or CD3 and CD46 (SCR4) or unlabeled as negative controls (29). The gating strategy is reported in Supplementary Figure 1.

Samples were acquired with FACSAria or LSR-Fortessa X-20 cytofluorimeter (BD) and analyzed using FlowJo software (BD).

Samples were labeled with the VIABILITY dye probe to exclude dead cells from analysis $10 \mathrm{~min}$ before acquisition.

FMO (Fluorescence minus one) was used to analyze samples. Samples were gated in single cells, and $\mathrm{T}$ live cells were then analyzed for the specific expression of CD46 [as median fluorescence intensity (MFI)] for SCR1, or for SCR4. CD46 expression was indicated as MFI percentage compared with the control.

\section{Complement Deposition on Human Microvascular Endothelial Cells}

A human microvascular endothelial cell line of dermal origin (HMEC-1) was plated on glass slides and used when confluent. Cells were activated with $10 \mu \mathrm{M}$ of adenosine $5^{\prime}$-diphosphate (ADP) for $10 \mathrm{~min}$ and then incubated for $4 \mathrm{~h}$ with serum diluted $1: 2$ with test medium [Hanks' Balanced Salt Solution (HBSS) with $0.5 \%$ bovine serum albumin (BSA)]. At the end of the incubation step, HMEC-1 were stained with FITC-conjugated rabbit antihuman C3c-complement or rabbit anti-human complement C5b-9 followed by FITC-conjugated secondary antibody. In each experiment, a pool of sera from healthy controls was tested parallel with the patient's serum. We verified the cellular integrity after exposure to serum samples in parallel slides in which HMEC-1 were stained with May-Grunwald Giemsa (30). A confocal inverted laser microscope was used for the acquisition of the fluorescent staining on the endothelial cell surface. Fifteen fields per sample were acquired, and the area with fluorescent staining was evaluated with automatic edge detection using builtin functions in the Image J software and expressed as pixel $^{2}$ per field analyzed. The fields with the lowest and highest values were excluded from calculation. Results were expressed as percentage of staining compared with control serum pool.

\section{Statistical Analysis}

MedCalc software was used for statistical tests. Fisher's exact test was used to compare the frequency of CD46 RVs between aHUS patients and healthy control populations. Chi-square test or Fisher's exact test was used to calculate the risk of $\mathrm{CFH}-\mathrm{H} 3$ and $C D 46_{G G A A C}$ haplotypes to increase the risk of developing aHUS. The results of C5b-9 deposition on activated HMEC were expressed as mean $\pm \mathrm{SE}$ and analyzed by ANOVA.

$P$-values of less than 0.05 were considered statistically significant.

\section{RESULTS}

\section{c.286+2T>G Is the Most Frequent CD46 Rare Variant in Atypical Hemolytic Uremic Syndrome and Is Associated With Incomplete Penetrance}

Screening of complement disease-associated genes in 485 unrelated patients with primary aHUS (herein defined aHUS) identified RVs in 189 cases. Specifically, 17\% of patients carry CFH RVs; $7 \%$ CFH-CFHR rearrangements; $8 \%$ RVs in CD46; and $4,8,2$, and $1 \%$ in $C F I, C 3, C F B$, and $T H B D$ genes, respectively. In addition, in $10 \%$ of patients, we identified anti-FH antibodies.

We identified 15 CD46 RVs in 39 patients. Of these, 20\% ( $n$ $=8)$ exhibited additional RVs in CD46 $(n=3)$ and/or in other complement genes $(n=5)$ (Table 1). Nonsense and frameshift RVs were found in 13 aHUS patients, whereas no non-sense or frameshift RVs were found in any of the 319 healthy controls (13/485 vs. $0 / 319 ; P=0.002)$.

c. $286+2 \mathrm{~T}>\mathrm{G}$ is the most frequent $\mathrm{RV}$ that we identified in aHUS patients of our Registry and is significantly overrepresented in patients compared with controls (patients $13 / 485$ vs: healthy controls $0 / 319, P=0.002$; ExAC controls 4/60412, $P=1 \times 10^{-6}$ ) (Table 1). Patients carrying this RV had an age of onset ranging from 1 to 58 years. Through the genetic analysis of seven pedigrees, we found 25 subjects carrying the c. $286+2 \mathrm{~T}>\mathrm{G}$ variant. Given that only seven individuals in the above pedigrees developed the disease, the penetrance of aHUS in c. $286+2 \mathrm{~T}>\mathrm{G}$ carriers is $28 \%$.

Among the seven studied pedigrees, we further focused on the large family identified as \#646 as a prototype of incomplete penetrance associated with the c.286+2T $>\mathrm{G}$ variant (Figure 1). In this pedigree, the proband was born from non-consanguineous, healthy parents. After an episode of acute gastroenteritis at 29.5 years of age, the man developed hypertension, jaundice, and thrombocytopenia (platelet count $25,000 / \mu \mathrm{l})$ with borderline serum creatinine levels $(1.2$ $\mathrm{mg} / \mathrm{dl})$ and normal $\mathrm{Hb}$ levels $(15 \mathrm{~g} / \mathrm{dl})$. The episode resolved spontaneously, platelet count normalized $(293,000 / \mu \mathrm{l})$, and $\mathrm{Hb}$ levels and renal function were normal $(16.6 \mathrm{~g} / \mathrm{dl}$ and $1.1 \mathrm{mg} / \mathrm{dl}$, respectively) (Figure 2). At age 32, he was hospitalized with a fever and jaundice. Laboratory results revealed a low platelet count $(12,000 / \mu \mathrm{l}$, Figure 2$)$, an increased LDH level (1,619 U/L), hyperbilirubinemia, fragmented red cells (schistocytes), and slightly elevated serum creatinine levels $(1.36 \mathrm{mg} / \mathrm{dl})$. A clinical diagnosis of aHUS was made. After 10 plasma exchanges and oral therapy with high doses of steroids $(1 \mathrm{mg} / \mathrm{kg})$, the hematologic features improved but renal function worsened (creatinine levels up to $2.9 \mathrm{mg} / \mathrm{dl}$, Figure 2). The patient continued steroid therapy, leading to improvement in renal function (serum creatinine: $1.5 \mathrm{mg} / \mathrm{dl}$ ) and an increase in platelet numbers $(203,000 / \mu$ l, Figure 2). After 3 months, serum creatinine was 4 $\mathrm{mg} / \mathrm{dl}$ (Figure 2), and the patient underwent a kidney biopsy, which showed thrombotic microangiopathy with ischemic nephropathy. Two months later, he had an aHUS relapse with severe thrombocytopenia $(44,000 / \mu \mathrm{l})$ severe renal failure (serum creatinine $10.6 \mathrm{mg} / \mathrm{dl}$, Figure 2) and lower than normal C3 
TABLE 1 | List of CD46 rare variants (RVs; variants with minor allele frequency $<0.001$ in 1000 Genomes and ExAC databases and with CADD phred score $\geq 10$ ) identified in 485 atypical hemolytic uremic syndrome (aHUS) patients recruited through the International Registry of HUS/TTP.

\begin{tabular}{|c|c|c|c|c|c|c|c|c|c|c|c|}
\hline Exon & $C D 46$ rare variants & $\begin{array}{l}\text { Patients } \\
(n=485)\end{array}$ & $\begin{array}{c}\text { Ctrs } \\
(n=319)\end{array}$ & $\begin{array}{c}P \text { - } \\
\text { value }\end{array}$ & dbSNP rs & HGMD & $\begin{array}{c}1,000 \mathrm{~K} \\
\text { frequency }\end{array}$ & $\begin{array}{l}\text { ExAC global } \\
\text { frequency }\end{array}$ & $\begin{array}{l}\text { Pathogenic } \\
\text { in functional } \\
\text { studies }\end{array}$ & CADD & $\begin{array}{c}\text { Variant } \\
\text { classification }\end{array}$ \\
\hline Intron 1 & c.98-1G>C (p.C35X) & 4 & 0 & 0.16 & rs1441937053 & CS064376 & NA & NA & Yes $^{1}$ & 24.1 & $\mathrm{P}$ \\
\hline Exon2 & c.104G >A (p.C35Y) & $3^{a}$ & 0 & 0.28 & rs121909591 & CM062498 & NA & $8.26 \times 10^{-6}$ & Yes $^{1}$ & 24.5 & LP \\
\hline Exon2 & c. $175 \mathrm{C}>\mathrm{T}(\mathrm{p} . \mathrm{R} 59 \mathrm{X})$ & $6^{b}$ & 0 & 0.09 & rs121909590 & CM062495 & NA & NA & Yes $^{1}$ & 24.5 & $\mathrm{P}$ \\
\hline Exon2 & c.192_198delinsC (p.C64fs) & 1 & 0 & 1.00 & NA & CX064751 & NA & NA & NA & 22.5 & LP \\
\hline Intron 2 & c. $286+2 T>G$ & $13^{c}$ & 0 & 0.002 & rs769742294 & CS066620 & NA & $3.3 \times 10^{-5}$ & Yes $^{2}$ & 23.7 & $P$ \\
\hline Intron 2 & c. $287-2 A>G$ & $3^{d}$ & 0 & 0.28 & rs759813089 & CS064377 & NA & $3.1 \times 10^{-5}$ & Yes $^{1}$ & 23.9 & LP \\
\hline Exon3 & c.295T>C (p.C99R) & 1 & 0 & 1.00 & NA & CM062496 & NA & NA & Yes $^{1}$ & 23.8 & $\mathrm{P}$ \\
\hline Exon3 & c.307C>T (p.R103W) & 1 & 0 & 1.00 & rs1486782648 & CM050660 & NA & NA & Yes $^{3}$ & 10.3 & US \\
\hline Intron 4 & c. $475+1$ 4delGTAA & $1^{e}$ & 0 & 1.00 & NA & CD136074 & NA & NA & NA & 16.8 & NA \\
\hline Exon 5 & c.565T>G (p.Y189D) & $4^{f}$ & 0 & 0.16 & rs202071781 & CM103418 & $1.99 \times 10^{-4}$ & $8.2 \times 10^{-6}$ & Yes $^{2}$ & 23.8 & LP \\
\hline Exon 5 & c.648G >C (p.W216C) & 1 & 0 & 1.00 & NA & CM103419 & NA & NA & NA & 24.9 & NA \\
\hline Exon 6 & c.685C>T (p.R229X) & 1 & 0 & 1.00 & rs1553251787 & CM1516829 & NA & NA & NA & 35 & LP \\
\hline Exon 6 & c.799-800delAC (p.T267fs) & 1 & 0 & 1.00 & NA & CD034158 & NA & NA & Yes $^{4}$ & 15.03 & $\mathrm{P}$ \\
\hline Exon 6 & $\begin{array}{l}\text { c.815_832delinsATT+ } \\
\text { c.841C>A (p.272- } \\
\text { 276del+D277N+P278S) }\end{array}$ & 1 & 0 & 1.00 & NA & CX064752 & NA & NA & Yes $^{1}$ & 25.4 & NA \\
\hline Exon 6 & c.725T>G (p.F242C) & 19 & 0 & 1.00 & NA & CM062499 & NA & NA & Yes $^{1}$ & 22.3 & $\mathrm{P}$ \\
\hline
\end{tabular}

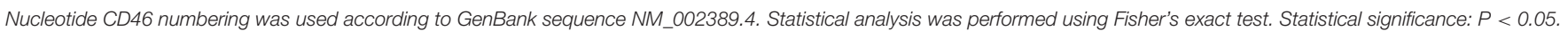
Italic characters indicate statistically significant values.

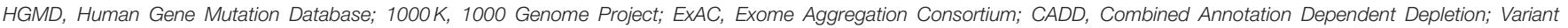

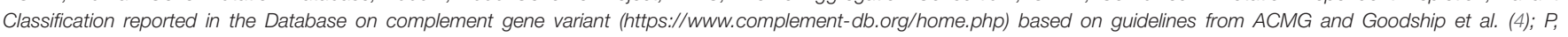
pathogenic; LP, likely pathogenic; US, uncertain significance; NA, not available.

${ }^{a}$ A patient (\#F106) carries two additional RVs (CD46 p.R59X; FH p.R1210C).

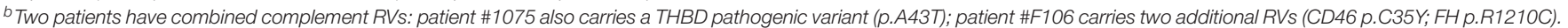

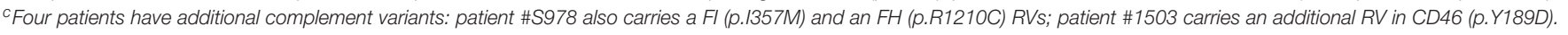
Patient \#1873 also carries an FH RV (p.N516K). Patient \#1793 also carries a FI RV (p.R317Q).

${ }^{d}$ A patient (\#657) also carries a FI RV (p.L484Vfs3X).

e This patient (\#1430) carries an additional CD46 RV (p.Y189D).

${ }^{f}$ Two patients (\#1430 and \#1503) also carry additional complement RVs (\#1430: c.475+1_delGTAA; \#1503: c.286+2T>G).

gThis patient (\#F169) also carries an FH RV (p.G1194D).

${ }^{1}$ Caprioli et al. (23).

${ }^{2}$ Fremeaux-Bacchi et al. (24).

${ }^{3}$ Fang et al. (31).

${ }^{4}$ Noris et al. (17).

and C4 levels (44 and $4 \mathrm{mg} / \mathrm{dl}$, respectively). He was treated with plasma exchange and steroid therapy and underwent hematological remission but developed ESRF requiring chronic hemodialysis. One year later, C3 and C4 serum levels were normal, $\mathrm{Hb}$ levels were borderline (between 11 and $11.9 \mathrm{~g} / \mathrm{dl}$ ), and the platelet count was normal (Table 2).

At age 37, the patient underwent a cadaveric renal transplantation with prophylactic plasma exchange to prevent post-transplant recurrence (Figure 2). The patient received an induction treatment with low doses of thymoglobulin and basiliximab, and maintenance immunosuppression with steroids, cyclosporine, and azathioprine. Hypertension was treated with atenolol and nifedipine. On day 9 post-transplant, the platelet count and $\mathrm{Hb}$ level were normal, and serum creatinine was $1.6 \mathrm{mg} / \mathrm{dl}$. At the last follow-up, 5 years after transplantation, blood pressure was normal (136/72 $\mathrm{mmHg}$ ), serum creatinine was $1.43 \mathrm{mg} / \mathrm{dl}$, and the platelet count and $\mathrm{Hb}$ levels were within normal ranges, while proteinuria was absent (0.08 g/24 h).
The proband carries the CD46 c.286+2T>G RV in heterozygosity. The family history is negative for aHUS and other kidney diseases. Genetic analysis for the c.286+2T $>\mathrm{G}$ variant was extended to 16 healthy relatives. As shown in Figure 1 (pedigree \#646), the c.286+2T>G variant is of paternal origin. Surprisingly, the proband's unaffected father (III-7) and one paternal aunt (III-6) are homozygous for the c. $286+2 \mathrm{~T}>\mathrm{G}$ RV. Furthermore, six paternal relatives are healthy carriers of the same variant in heterozygosity (Figure 1).

Sequencing of other complement aHUS-associated genes (CFH, CFI, C3, CFB, THBD, and CFHR5) in the proband and his parents did not reveal additional RVs. The proband has a normal copy number of $\mathrm{CFH}-\mathrm{CFHR}$ genes. The assay for anti-FH antibodies that was done before transplantation showed negative results.

We then investigated whether genetic modifiers previously associated with aHUS, including the $\mathrm{CFH}-\mathrm{H} 3$ and the 


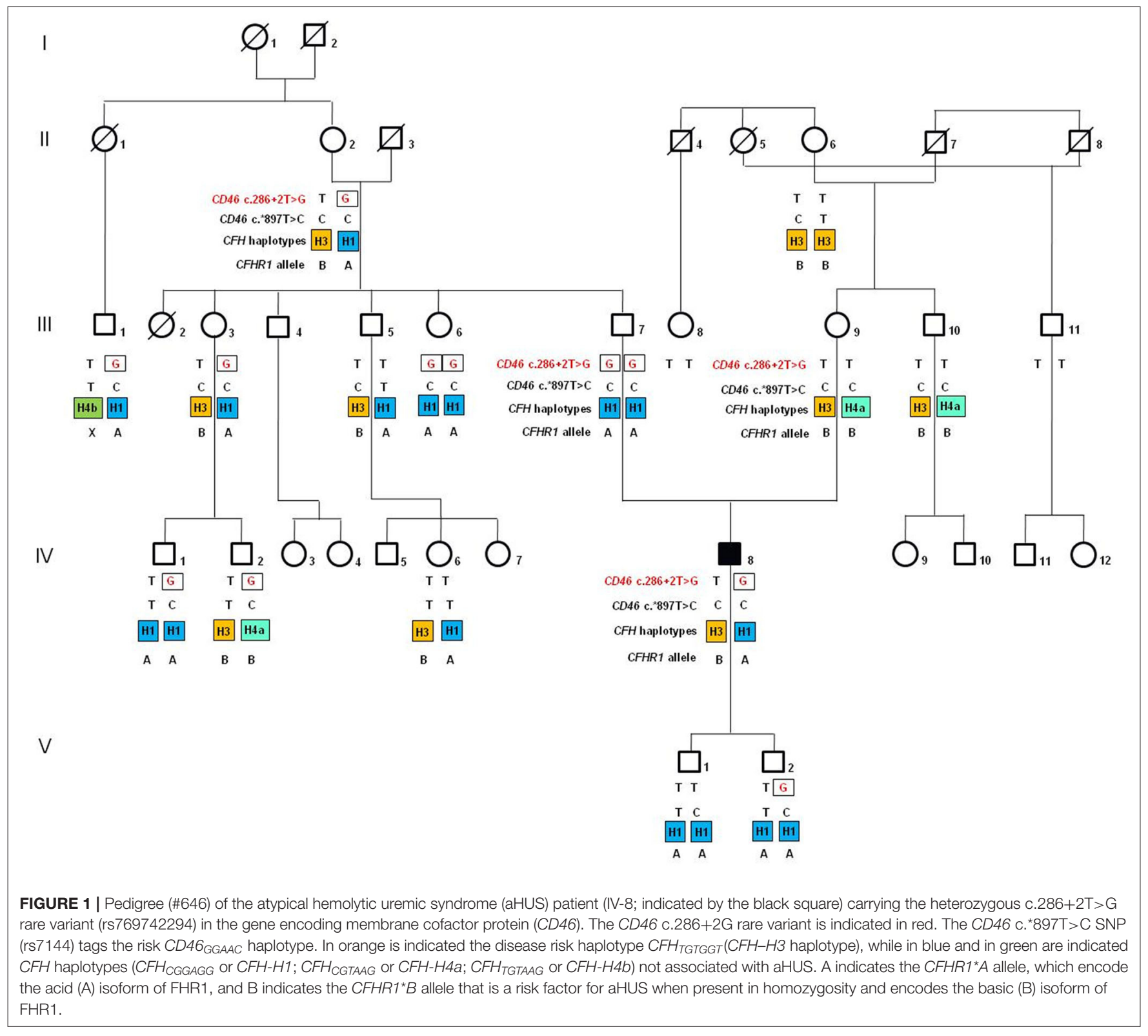

CD46 ${ }_{G G A A C}$ haplotypes (32-35), and the CFHR ${ }^{*} B$ allele (28) could account for disease penetrance in family \#646. The proband is heterozygous for the CFH SNPs of the risk H3 haplotype $\left(C F H_{T G T G G T}\right)$, which he inherited from his mother. In addition, he is homozygous for the c. ${ }^{*} 897 \mathrm{~T}>\mathrm{C}$ SNP (rs7144), which tags the $C D 46_{G G A A C}$ risk haplotype and was inherited from both parents, who are homozygous for this SNP. Finally, he is heterozygous for the $C F H R 1^{*} B$ allele (Figure 1).

Unlike the proband, his father does not carry the risk $\mathrm{CFH}-\mathrm{H} 3$ haplotype. Indeed, he is homozygous for the neutral $\mathrm{CFH}-\mathrm{H1}$, previously found with the same frequency in aHUS patients and in the control population $(34,36)$. In addition, the father does not carry the $C F H R 1^{*} B$ allele. However, as shown in Figure 1, two unaffected adult paternal relatives who are heterozygous for c.286+2T>G RV (II-2, the paternal grandmother and III-3, a paternal aunt; 83 and 49 years old, respectively) share the same risk factors as the proband. Indeed, they have one copy of $\mathrm{CFH}-\mathrm{H} 3$, two copies of the $C D 46_{G G A A C}$, and one copy of the $C F H R 1^{*} B$. These data indicate that the presence of $C F H$ and $C D 46$ risk haplotypes and $C F H R 1^{*} B$ alleles is not enough to explain the disease in c. $286+2 \mathrm{~T}>\mathrm{G}$ carriers.

We extended the analysis of $C F H$ and $C D 46$ risk haplotypes to the other aHUS patients and their available unaffected relatives carrying the CD46 c.286+2T>G RV. We found no significant association between the presence of $\mathrm{CFH}-$ H3 $(P=0.29)$ or $C D 46_{G G A A C}(P=0.12)$ haplotypes and the disease (Table 3), confirming the results obtained in pedigree \#646. 


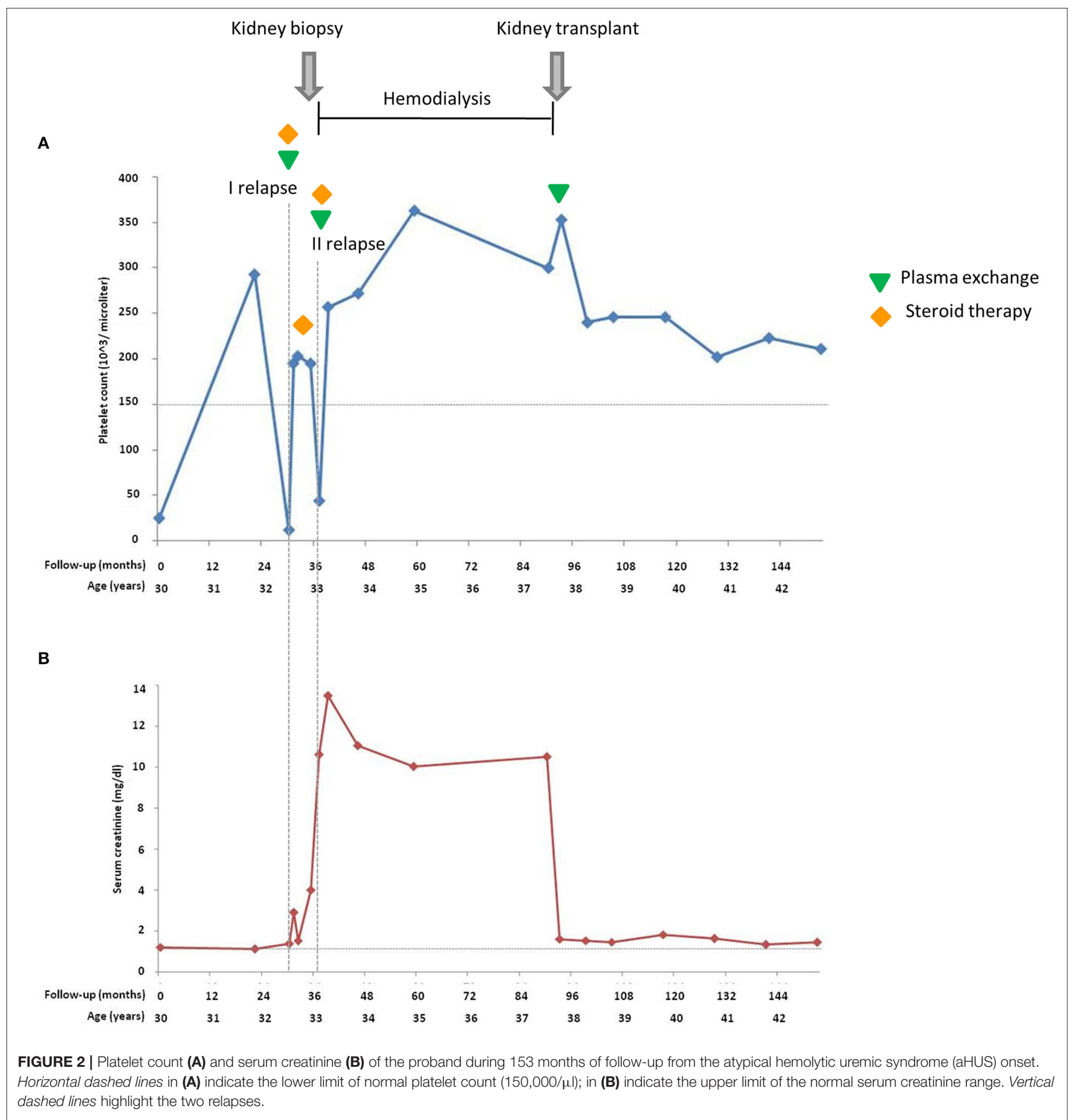

\section{In Pedigree \#646, the CD46 c.286+2T>G} Rare Variant Causes the Formation of Two Abnormal mRNA Variants, Leading to Reduced Cell Surface Protein CD46

\section{Expression}

The c. $286+2 \mathrm{~T}>\mathrm{G}$ RV is in the donor splice site of exon 2 of CD46 coding for short consensus repeat 1 (SCR1), which is one of the four extracellular complement regulatory domains of the protein. The variant has already been described as affecting exon 2 splicing $(24,25)$. In 2006, Fremeaux-Bacchi et al. (24) described that it results in aberrant mRNA that lacks 144 bp of exon 2 and encodes a protein that is missing 48 amino acids in the SCR1 domain in phase with the wild-type protein sequence. In 2010 , Maga et al. (25) provided different results and showed that the c. $286+2 \mathrm{~T}>\mathrm{G}$ RV leads to a frameshift at p.R96 (SCR2) of the 
TABLE 2 | Clinical, complement, genetic, and CD46 expression data in the patient and his asymptomatic relatives.

\begin{tabular}{|c|c|c|c|c|c|c|c|c|c|c|c|c|c|c|c|}
\hline \multirow[b]{2}{*}{$\begin{array}{l}\text { Disease } \\
\text { status }\end{array}$} & \multirow[b]{2}{*}{ Subject } & \multirow[b]{2}{*}{ Gender } & \multirow[b]{2}{*}{$\begin{array}{c}\text { Age } \\
\text { (years) }^{\mathrm{a}}\end{array}$} & \multirow{2}{*}{$\begin{array}{c}\frac{\text { Genetic data }}{C D 46:} \\
\text { c.286+2T>G }\end{array}$} & \multicolumn{4}{|c|}{ Clinical parameters } & \multicolumn{5}{|c|}{ Complement parameters } & \multicolumn{2}{|c|}{ CD46 protein expression ${ }^{\dagger}$} \\
\hline & & & & & $\begin{array}{l}\text { Platelets } \\
\left(\times 10^{3} / \mu\right)^{\mathrm{b}}\end{array}$ & $\begin{array}{l}\text { LDH } \\
(\text { IU/L) }\end{array}$ & $\begin{array}{c}\mathrm{Hb} \\
(\mathrm{g} / \mathrm{dl})^{\mathrm{d}}\end{array}$ & $\begin{array}{c}\mathrm{sCr} \\
(\mathrm{mg} / \mathrm{dl})^{\mathrm{e}}\end{array}$ & $\begin{array}{c}\text { C3 } \\
(\mathrm{mg} / \mathrm{dl})^{\mathrm{f}}\end{array}$ & $\begin{array}{c}\mathrm{C} 4 \\
(\mathrm{mg} / \mathrm{dl})^{\mathrm{g}}\end{array}$ & $\begin{array}{l}\text { sC5b-9 } \\
(\mathrm{ng} / \mathrm{ml})^{\mathrm{h}}\end{array}$ & $\begin{array}{l}\text { C3 depositsi } \\
\text { (\% of } \\
\text { control) }\end{array}$ & $\begin{array}{c}\text { C5b-9 } \\
\text { depositsi (\% } \\
\text { of control) }\end{array}$ & $\begin{array}{l}\text { With anti-SCR1 } \\
\text { antibody (\% of } \\
\text { control) }\end{array}$ & $\begin{array}{l}\text { With anti-SCR4 } \\
\text { antibody (\% of } \\
\text { control) }\end{array}$ \\
\hline Affected & $\mathrm{N}-8$ & M & 34 & $\mathrm{TG}$ & 363 & 434 & 11.9 & 10.03 & 114 & 47 & 250.7 & 380 & 464 & 46 & 63 \\
\hline Unaffected & III-7 & M & 57 & GG & 204 & 392 & 14.6 & 0.83 & nd & nd & 136.2 & 135 & 104 & 7 & 15 \\
\hline Unaffected & III-9 & $\mathrm{F}$ & 52 & $\pi$ & 226 & 334 & 13.1 & 0.76 & nd & nd & 140.1 & 275 & 358 & 95 & 100 \\
\hline Unaffected & $\|-2$ & $\mathrm{~F}$ & 82 & TG & 209 & 454 & 13.4 & 1.13 & nd & nd & nd & nd & nd & 37 & 54 \\
\hline Unaffected & III-6 & $\mathrm{F}$ & 49 & $G G$ & 277 & 376 & 12.4 & 0.56 & nd & nd & nd & nd & nd & 8 & 9 \\
\hline Unaffected & III-3 & $\mathrm{F}$ & 60 & $\mathrm{TG}$ & 151 & 401 & 13.4 & 0.81 & nd & nd & nd & nd & nd & 40 & 56 \\
\hline Unaffected & III-5 & M & 50 & $\pi$ & 151 & 437 & 14.1 & 0.81 & nd & nd & nd & nd & nd & 91 & 100 \\
\hline Unaffected & $V-1$ & M & 7 & $\pi$ & 215 & nd & 13.5 & 0.47 & nd & nd & nd & nd & nd & 97 & nd \\
\hline Unaffected & || $\mid-1$ & M & 51 & $\mathrm{TG}$ & 245 & 482 & 16 & 0.76 & nd & nd & 211.5 & nd & 103 & nd & nd \\
\hline Unaffected & III-10 & M & 55 & $\mathrm{TG}$ & nd & 334 & nd & 1.08 & nd & nd & nd & 193 & 337 & nd & nd \\
\hline
\end{tabular}

${ }^{a}$ At this age, the proband was in hematological remission and chronic hemodialysis. Age of relatives refers to the data of the visit done at our center for genetic, clinical, and complement CD46 expression analyses. Abbreviations and limit of normal range.

b $150-400 \times 10^{3} / \mu l$.

${ }^{C} L D H$, lactate dehydrogenase: $266-500 \mathrm{IU} / \mathrm{L}$.

${ }^{d} H \mathrm{Hb}$, hemoglobin: 14-18 g/dl (men), 12-16 g/dl (women).

escr, serum creatinine: $0.55-1.25 \mathrm{mg} / \mathrm{dll}$.

C3: $79-170 \mathrm{mg} / \mathrm{dl}$

${ }^{{ }^{n}}$ Normal plasma sC5b9 levels: $\leq 400 \mathrm{ng} / \mathrm{ml}$.

iExpressed as percentage of control. Limit of normal range $<150 \%$.

${ }^{\dagger}$ CD46 protein levels in CD3+ positive peripheral blood mononuclear cells (PBMCS). Values are expressed as percentage median fluorescence intensity in control CD3+ PBMCs. Data are mean of results of 2/3 experiments. nd, not done. 
TABLE 3 | Analysis showing that $\mathrm{CFH}-\mathrm{H3}$ and $C D 46_{G G A A C}$ haplotypes are not associated with $C D 46$ c.286+2T>G rare variant.

\begin{tabular}{|c|c|c|c|c|c|c|c|c|}
\hline \multirow[b]{2}{*}{ Status } & \multicolumn{4}{|c|}{ CFH-H3 haplotype } & \multicolumn{4}{|c|}{$C D 46$ c. ${ }^{\star} 897 T>C$} \\
\hline & het & hom & No CFH H3-haplotype & Total subjects screened & TT & TC & CC & Total subjects screened \\
\hline Affected & 3 & 3 & 3 & 9 & 0 & 1 & 10 & 11 \\
\hline \multirow[t]{2}{*}{ Unaffected } & 7 & 1 & 5 & 13 & 0 & 6 & 7 & 13 \\
\hline & \multicolumn{4}{|c|}{$P=0.293$} & \multicolumn{4}{|c|}{$P=0.124$} \\
\hline
\end{tabular}

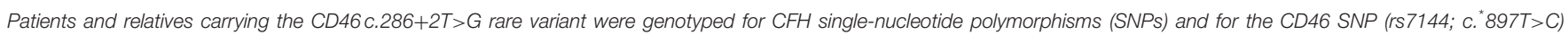
tagging the $C D 46_{G G A C}$ haplotype.

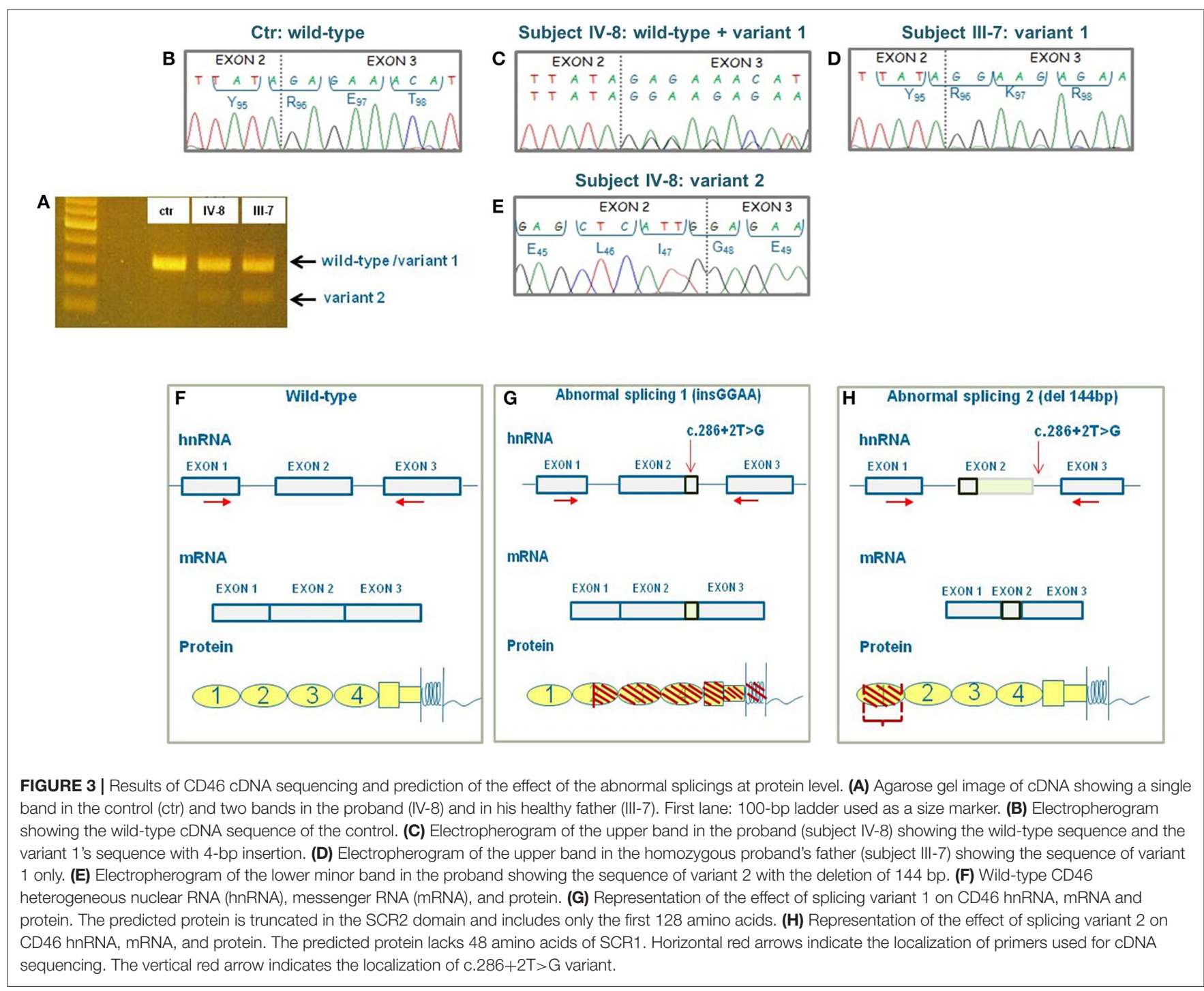

protein, with the addition of several amino acids, followed by a premature truncation at position p.129X (SCR2).

To clarify the effect of the c. $286+2 \mathrm{~T}>\mathrm{G}$ variant in pedigree \#646 and to evaluate whether there was any difference in the abnormal splicing between the proband and the unaffected carriers, we extracted RNA from PBMCs from the proband and his relatives. cDNA amplification using the forward primer located on exon 1 and reverse primer located on exon 3 revealed two different bands on agarose gel electrophoresis in the proband and in all carriers (Figure 3A). Sequencing of the two bands revealed the wild-type sequence and two variants in the heterozygous proband, as well in the heterozygous healthy relatives. The upper band includes both the wild-type sequence and a second sequence (variant 1 ) with a 4-bp insertion, which 


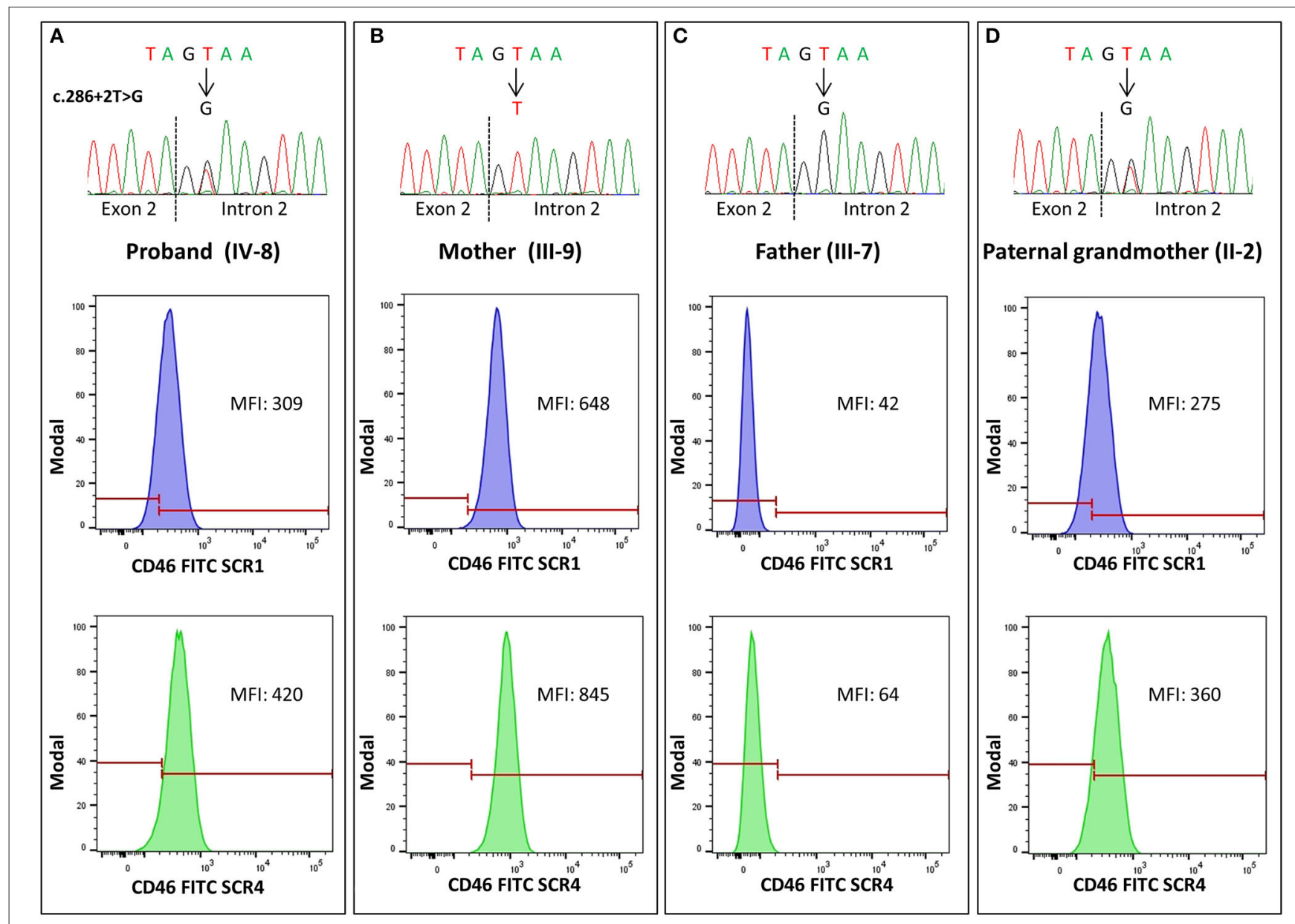

FIGURE 4 | Representative histograms of flow cytometry analysis in pedigree \#646, performed with anti-SCR1 and anti-SCR4 antibodies showing levels of CD46 on $\mathrm{CD} 3+$ peripheral blood mononuclear cells (PBMCs), expressed as median fluorescence intensity (MFI). The heterozygous carriers of the $286+2 \mathrm{~T}>\mathrm{G}$ rare variant [the proband IV-8, (A), and the paternal grandmother II-2, (D)] showed about 50\% CD46 expression compared with the wild-type mother [subject III-9, (B)], while in the homozygous patient's father [subject III-7, (C)], a severe reduction of CD46 expression (<8\% compared with the wild-type mother) was observed. The electropherograms of DNA sequences in the proband and his relatives are shown on the top of each panel.

corresponds to the variant described by Maga et al. (25) (control: Figure 3B, proband: Figure 3C). cDNA sequence analysis of the upper band from two homozygous relatives showed the variant 1 sequence, but not the wild-type sequence (Figure 3D). The sequence of the minor band (variant 2) corresponds to the splicing variant with the 144-bp deletion described by FrémeauxBacchi et al. (24) (Figure 3E). These data demonstrate that (1) the two aberrant mRNA splicing isoforms coexist both in the proband and in his unaffected carrier relatives; (2) variant 1 (with the 4-bp insertion) is the predominantly expressed variant both in heterozygous and homozygous carriers; and (3) in the homozygous unaffected carriers, no appreciable wild-type mRNA is transcribed. Thus, the characterization of abnormal RNAs and their proportion in the pedigree do not explain the incomplete penetrance of the c.286+2T $>\mathrm{G} \mathrm{RV}$ in this pedigree.

The predicted effect of the two aberrant mRNA splicing isoforms on protein sequence in respect to wild-type protein is shown in Figures $\mathbf{3 F}-\mathbf{H}$. To investigate whether the c. $286+2 \mathrm{~T}>\mathrm{G}$ RV affected the levels of CD46 protein on cell surfaces in the proband and in his unaffected carrier relatives differentially, we performed fluorescence-activated cell sorting (FACS) studies in peripheral blood leukocytes (Table 2 and Figure 4). With the use of an anti-SCR1 antibody, the MFI on PBMCs from the proband was $46 \%$, compared with that found on PBMCs from healthy controls (Table 2). Similar levels of MFI were observed on PBMCs from the heterozygous healthy carriers (37\% in II-2 and $40 \%$ in III-3, Table 2). These results indicate that the c. $286+2 \mathrm{~T}>\mathrm{G}$ RV severely impairs cell surface protein expression.

Impressively, the PBMCs from the two healthy homozygous relatives (the father, III-7 and the paternal aunt, III-6) exhibited $<8 \%$ of normal CD46 expression (Table 2), demonstrating an almost complete CD46 deficiency.

Since the anti-SCR1 antibody cannot recognize the less abundant splicing variant 2 that lacks 48 amino acids in SCR1, we repeated the FACS analysis using an antibody targeting the 
A

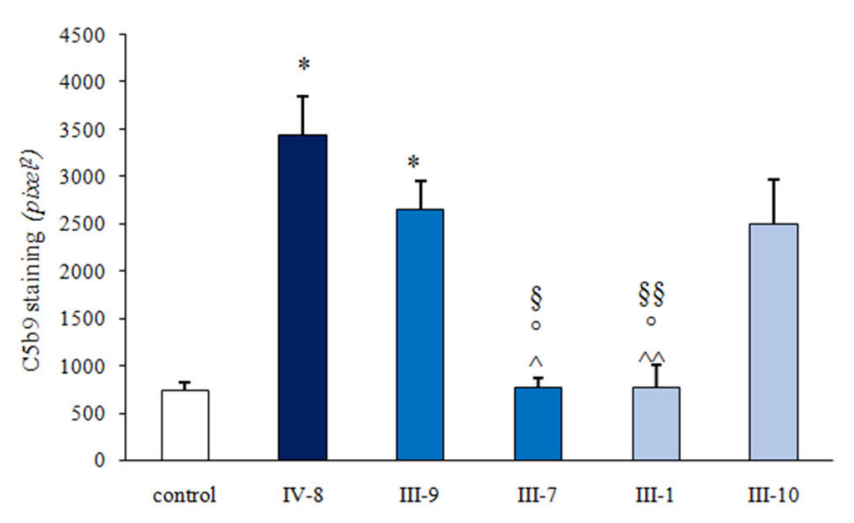

C

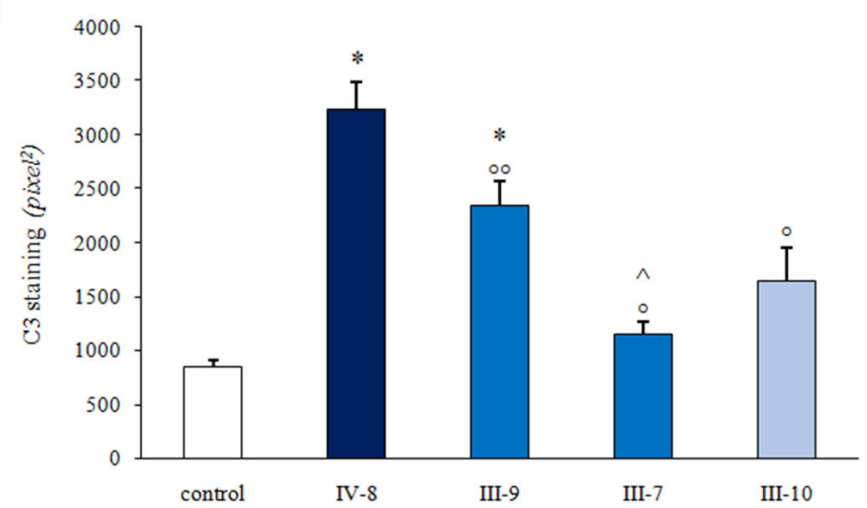

B
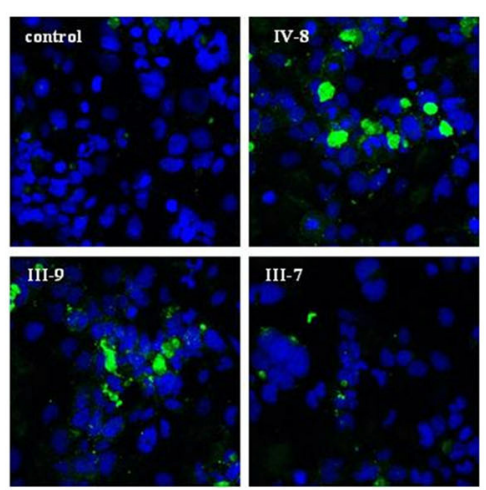

D
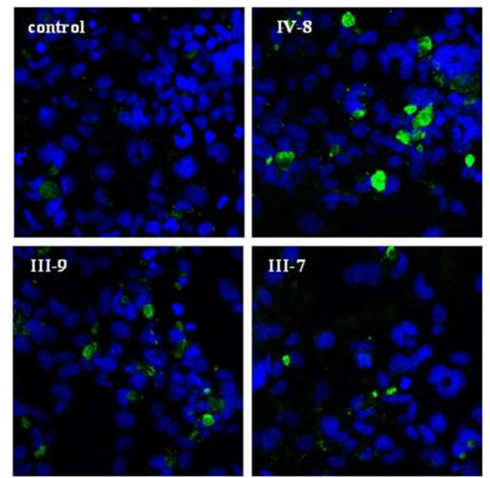

FIGURE 5 | Serum-induced C3 and C5b-9 deposition on human microvascular endothelial cell line (HMEC-1) activated with adenosine 5'-diphosphate (ADP). (A,C) Histograms show the quantification of C5b9 (A) or C3 (C) staining on activated HMEC-1 after $4 \mathrm{~h}$ of incubation with the serum from a healthy control (control), the patient (IV-8; heterozygous for CD46 c.286+2T>G variant), patient's father (III-7; homozygous for CD46 c.286+2T>G variant), the patient's mother (III-9; with no complement RVs), a paternal relative (III-1; heterozygous for CD46 c.286+2T>G variant), and a maternal relative (III-10; with no complement RVs). Data are means \pm SE; ${ }^{\star} P<0.0001$ vs. control; ${ }^{\circ} P<0.0001$ vs. IV-8; ${ }^{\circ} P<0.01$ vs IV-8; $\wedge P<0.0001,{ }^{\wedge} \wedge P<0.001$ vs. III-9; ${ }^{\S} P<0.01$, ${ }^{\S \S} P<0.05$ vs. III-10. Representative confocal microscopy images show strong C5b-9 (B) and C3 (D) staining (green) on activated H-MEC1 induced by serum from the patient (IV-8) and from his unaffected mother (III-9) but not by the serum from the proband's father (III-7; B,D). The blue color indicates the 4'-6-diamidino-2-phenylindole (DAPI) staining of cell nuclei.

SCR4 of CD46. CD46 surface expression was about $63 \%$ normal in the proband, 54-56\% in the heterozygous healthy carriers, and $12 \%$ in the homozygous family members (Table 2 ).

Thus, with both antibodies, CD46 protein expression was similar and close to half-normal levels in the proband and the heterozygous carriers, whereas healthy homozygous relatives had an almost complete CD46 deficiency.

In the wild-type family members, the CD46 expression on PBMCs was similar to that observed in healthy controls with both anti-SCR1 and anti-SCR4 antibodies (Table 2).

Representative FACS histograms are shown in Figure 4.

\section{In Pedigree \#646, a Circulating Defect of Maternal Origin Causes Complement Dysregulation on Endothelial Cells}

The complement system is constituted by over 50 components, and its activation is strictly regulated by circulating and membrane bound proteins to prevent injury to host cells. We hypothesized that a defect in a circulating factor resulting in complement dysregulation at the endothelial cell level could have synergized with CD46 RV in inducing the disease in the proband. To address this issue, we used a specific ex vivo test in which serum from patients with aHUS, studied either during the acute phase or in remission, induces intense deposition of complement products on microvascular endothelial cells (HMEC-1) $(37,38)$. We exposed ADP-activated HMEC-1 to serum from the proband and from his relatives and evaluated the surface area covered by deposits of the terminal complement complex C5b-9. Serum from the proband (IV-8 in Figure 5), collected while he was in remission when he was on chronic hemodialysis, deposited significantly more C5b-9 on HMEC-1 than control serum (464\% of C5b-9 deposits recorded with a pool of sera from healthy controls, Figures 5A,B). Similar results (589\%) were obtained with serum collected 2 weeks after kidney transplantation. 
Serum from the unaffected father (III-7), who is homozygous for the CD46 RV, and serum from a heterozygous unaffected relative (III-1) did not increase endothelial C5b-9 deposits (Figures 5A,B). At variance, abnormally high C5b-9 deposits were induced on HMEC-1 by serum from the proband's mother (III-9; $358 \%$ of control sera) and from a maternal uncle (III10; 356\%) who do not carry the CD46 RV (Figures 5A,B). These results indicate that the proband inherited from his mother an abnormality in a circulating factor that predisposes to complement activation on endothelial cells.

Similar results were obtained when we repeated the ex vivo test on activated HMEC-1 using an anti-C3c antibody to detect deposits of $\mathrm{C} 3$ activation products. Results showed that serum from the proband in remission induced significantly higher C3 deposits than the pool of control sera (380\%) (Figures 5C,D). Elevated endothelial C3 deposits were also observed on cells incubated with sera from the proband's mother (III-9, 275\%) and the maternal uncle (III-10, 193\%) but not with the serum from the proband's father (III-7, 135\%) (Figures 5C,D).

\section{DISCUSSION}

Through a retrospective analysis of a cohort of 485 aHUS patients, we performed genetic, molecular, and functional studies to investigate the determinants of penetrance of aHUS associated with genetic abnormalities in CD46. This gene encodes a transmembrane glycoprotein that is highly expressed in all tissues, on endothelial cells, and on all circulating cells with the exception of erythrocytes, which regulates both the alternative and classical complement pathways, acting as cofactor for FI to degrade $\mathrm{C} 3 \mathrm{~b}$ and $\mathrm{C} 4 \mathrm{~b}$ and to prevent $\mathrm{C} 3$ activation on cell surfaces (39).

In this study, CD46 RVs were found in about $10 \%$ of aHUS patients. Consistent with data reported earlier by our group and others, aHUS-associated CD46 RVs cluster in the extracellular domains of the protein, which are involved in cell surface complement regulation $(21,40)$.

We focused on the splicing variant c. $286+2 \mathrm{~T}>\mathrm{G}$, which is the most frequent CD46 RV in our and other aHUS cohorts (21). The c. $286+2 \mathrm{~T}>\mathrm{G}$ is also present in the general population, and the allele frequency of this variant in European nonFinnish population is $6.02 \times 10^{-5}$. If this allele were fully penetrant, it would have resulted in $0.012 \%$ of population developing aHUS. However, the reported prevalence of aHUS is far lower, ranging between two to ten per million population $(0.0002-0.001 \%)$ (41), implying that the c. $286+2 \mathrm{~T}>\mathrm{G}$ is not enough to develop the disease. Consistently, through the analysis of our pedigrees, we have found several unaffected carriers of the c. $286+2 \mathrm{~T}>\mathrm{G}$ and that aHUS penetrance was lower than $30 \%$.

As a prototype of incomplete penetrance associated with c. $286+2 \mathrm{~T}>\mathrm{G} \mathrm{RV}$, we investigated in depth a large pedigree (\#646) from our cohort with nine carriers, of whom only one was affected by aHUS. The proband, as well as six unaffected family members, is heterozygous for the c.286+2T $>$ G RV, and surprisingly, the healthy proband's father and aunt were even homozygous for this variant. Bathia et al. (26) described the incomplete penetrance of the c. $286+2 \mathrm{~T}>\mathrm{G}$ RV in a family with three homozygous siblings, two of whom developed aHUS at 5 and 8 years of age but one of whom was still asymptomatic at age 10. The authors' hypothesis that the latter may develop HUS at a later age (26) is not supported by findings in our pedigree, showing two adults who are homozygous for this RV and are asymptomatic at 66 and 58 years of age at present.

Altogether, these data indicate that genetic deficiency of CD46 due to pathogenetic RVs is not enough to induce aHUS and that other genetic risk factors are likely important for disease manifestation.

This is consistent with the present and other published (12) findings that show that around $25 \%$ of aHUS patients with RVs in CD46 carry a second or third RV in other complement genes. Specifically, in $23 \%$ of patients with the c. $286+2 \mathrm{~T}>\mathrm{G}$ variant, we found RVs in other known disease-associated genes. However, this is not the case for the large pedigree \#646 described here, since the proband did not carry other RVs or anti-FH antibodies.

In addition to complement gene RVs, common genetic modifiers, such as the $\mathrm{CFH}-\mathrm{H} 3$ and $\mathrm{CD} 46_{G G A A C}$ haplotypes and the $C F H R 1^{*} B$ allele, may influence susceptibility to aHUS $(16,32-34,36)$. Indeed, the $C F H-H 3$ and $C D 46_{G G A A C}$ haplotypes and the homozygous $C F H R 1^{*} B$ allele have been reported more frequently in aHUS patients than in controls. It is significant that our group and others have shown that in some aHUS families the disease manifested only in individuals who inherited a complement RV from one parent and the $\mathrm{CFH}$ and/or CD46 risk haplotype from the other parent (32, 34,42 ). However, the above findings are not universally true, since in other families aHUS penetrance was still incomplete in carriers of complement RVs and both $\mathrm{CFH}-\mathrm{H} 3$ and $C D 46_{G G A A C}$ risk haplotypes, suggesting that the synergic effect of these haplotypes may depend on the specific concurrent RV (12).

Consistently, here, we have found that the proband of the large pedigree with the $286+2 \mathrm{~T}>\mathrm{G}$ RV carries the $\mathrm{CFH}-\mathrm{H} 3$ risk haplotype, the homozygous $C D 46_{G G A A C}$ haplotype, and one copy of the $C F H R 1^{*} B$ allele, but this combination does not explain penetrance, since the same risk factors are present in unaffected relatives who are carriers of the c. $286+2 \mathrm{~T}>\mathrm{G}$ RV. The finding that in the other pedigrees with the c. $286+2 \mathrm{~T}>\mathrm{G} \mathrm{RV}$ the $\mathrm{CFH}-$ $H 3$ and $C D 46_{G G A A C}$ did not segregate with aHUS confirms that the above haplotypes do not have a significant effect on the risk of aHUS in CD46 c. $286+2 \mathrm{~T}>\mathrm{G}$ carriers.

c. $286+2 \mathrm{~T}>\mathrm{G}$ is a splice variant and as such can affect mRNA processing and generate aberrant proteins with impaired structural and/or functional properties. However, different data on its effect have been reported. In one study, this RV was shown to cause an in-frame deletion generating a shorter CD46 protein that lacks part of SCR1 (24) and likely maintains a partial regulatory function. At variance, in another report, c. $286+2 \mathrm{~T}>\mathrm{G}$ was shown to have a greater impact, resulting in the premature truncation of CD46 at SCR2 with the loss of all the other complement regulatory SCRs and of the transmembrane and intracellular domains (25). Thus, we wondered whether differences in the mRNA and protein products of the abnormal 
splicing between the proband and the unaffected carriers could explain incomplete aHUS penetrance in our pedigree. However, this was not the case, since we found that the proband and all healthy carrier relatives express mRNAs encoding both the shorter and truncated CD46 variants and that the latter was prominent in all carriers. The finding that the proband and the heterozygous c. $286+2 \mathrm{~T}>\mathrm{G}$ carriers had approximately halfnormal CD46 levels on blood cells and homozygous carriers had an almost total CD46 deficiency confirmed at the protein level that the truncated variant was the main product of the c. $286+2 \mathrm{~T}>\mathrm{G}$ RV. Severe CD46 protein deficiency was also reported in a patient with aHUS and his healthy sister, both of whom were homozygous for another RV, CD46 c.286+1T $>\mathrm{G}$, affecting the same splice site (43). Together, these findings indicate that CD46 deficiency is not enough to induce the aHUS phenotype.

As multiple complement regulatory proteins, including the transmembrane decay-accelerating factor (DAF), protectin (CD59), and plasma factor $\mathrm{H}$ are expressed or bind to endothelial cell surfaces, the endothelium can regulate complement even when gene abnormalities cause impaired activity of one of them (44). This is supported by studies in blood outgrowth endothelial cells showing that the inhibition of CD46 with a specific antibody followed by exposure to normal human serum as a source of complement did not cause C3 deposition on cell surfaces (45).

In search of additional abnormalities in the proband of our pedigree that could predispose him to aHUS, we used an ex vivo assay of serum-induced complement activation on a cultured endothelial cell line (HMEC-1) [34], based on evidence that in aHUS the microvascular endothelium is the main target of complement dysregulation (2). In previous studies, the assay with ADP-activated HMEC-1 allowed us to specifically pick up genetic complement abnormalities that affect circulating regulators both in aHUS patients and in their unaffected relatives (37).

The finding here that serum from the proband, and also sera from the mother and a maternal uncle, caused extensive $\mathrm{C} 3$ and C5b-9 deposits on activated HMEC-1 indicates that the proband inherited from his mother a genetic abnormality that causes complement activation on endothelial cells.

At variance, the unaffected paternal relatives carrying the c. $286+2 \mathrm{~T}>\mathrm{G}$ CD $46 \mathrm{RV}$ had normal serum-induced complement deposition on endothelial cells, which is an expected finding because CD46 is a surface complement regulatory protein and the endothelial cell line used in the assay expresses normal CD46. Thus, the proband has two main genetic predisposing factors, the c.286+2T>G CD46 RV inherited from his father and a defect of maternal lineage that remains unknown and which, together with the $\mathrm{CFH}-\mathrm{H} 3$ and $\mathrm{CD} 46_{G G A A C}$ risk haplotypes, have synergized and induced aHUS. The finding that both the paternal relatives carrying the $c .286+2 \mathrm{~T}>\mathrm{G} C D 46$ variant and the maternal relatives with an abnormal complement deposition test are unaffected indicates that either genetic defect alone were not enough to induce aHUS.

Whole exome sequencing studies in this pedigree are required to identify the genetic defect inherited from the patient's mother, using segregation with the phenotype "elevated complement deposits" as criterion for selection of candidate variants.
Terminal complement activation associated with aHUS has been shown to activate platelets and neutrophils and to induce the formation of neutrophil-platelet aggregates $(46,47)$. Further $e x$ vivo studies with platelets and blood leukocytes from the proband and his relatives could also contribute to clarify the complex pathogenetic mechanisms leading to aHUS in this pedigree.

aHUS patients with CD46 RVs usually have a good prognosis. Although recurrences are frequent, spontaneous remissions are common and the long-term outcome appears to be good, with about $90 \%$ of patients maintaining normal renal function. The proband described here, however, had a severe disease course and developed ESRF, despite intensive plasma-exchange therapy. This phenotype closely resembles that of patients with combined RVs in CD46 and other complement genes (14), thus supporting the hypothesis that the proband inherited an additional genetic defect from his mother. The observation that the proband did not experience HUS recurrence in the kidney graft and exhibits good a graft function at the 5-year follow-up after transplantation can be explained by the transplant correcting the CD46 genetic defect, since endothelial cells within the kidney allograft express normal CD46. This finding also supports our interpretation that both the paternal CD46 variant and the unidentified maternal defect synergized to induce aHUS in this pedigree.

In conclusion, we demonstrate that $C D 46$ c. $286+2 \mathrm{~T}>\mathrm{G}$ is a variant with a severe functional effect and also confirm that CD46 deficiency alone is not sufficient to develop aHUS, even though it is a strong risk factor.

The results from this study are consistent with earlier reports in the literature (33) that have documented the complexity of genetic abnormalities associated with aHUS, which range from highly penetrant RVs and genomic rearrangements that affect CFH to RVs that cause aHUS only in the presence of other RVs and/or risk haplotypes. Combining genetic studies with the ex vivo test of complement activation on endothelium may contribute to explaining the determinants of penetrance in this complex disease.

\section{DATA AVAILABILITY STATEMENT}

The raw data supporting the conclusions of this article will be made available by the authors, without undue reservation, to any qualified researcher.

\section{ETHICS STATEMENT}

The studies involving human participants were reviewed and approved by Ethics Committee of the Azienda Sanitaria Locale, Bergamo, Italy. Written informed consent to participate in this study was provided by the participants' legal guardian/next of kin.

\section{AUTHOR CONTRIBUTIONS}

$\mathrm{RP}, \mathrm{MN}$, and GR designed research, interpreted data, and wrote the paper. RP, PI, MT, SG, EV, MA, CM, MG, and PC performed the research and analyzed the data. 
EB provided detailed clinical information of patients. $A B$ analyzed the data and critically revised the manuscript. All authors contributed to the article and approved the submitted version.

\section{FUNDING}

This work was partially supported by the European Union Framework Programme 7 (FP7)-EURenOmics project 305608 and by the Italian Ministero della Salute (RF-2016-02361720). $\mathrm{RP}$ and EV are recipients of a research contract from Progetto DDD Onlus-Associazione per la lotta alla DDD (Milan, Italy) and Cassa di Sovvenzioni e Risparmio fra il Personale della Banca D'Italia (Rome, Italy). PC is recipient of a fellowship from Fondazione Aiuti per la Ricerca sulle Malattie Rare ARMR ONLUS (Bergamo, Italy). The funding sources had no role in study design or in the collection, analysis, and interpretation of data, nor in the writing of the report or in the decision to submit the paper for publication.

\section{REFERENCES}

1. Noris M, Remuzzi G. Hemolytic uremic syndrome. J Am Soc Nephrol. (2005) 16:1035-50. doi: 10.1681/ASN.2004100861

2. Noris M, Remuzzi G. Atypical hemolytic-uremic syndrome. $N$ Engl J Med. (2009) 361:1676-87. doi: 10.1056/NEJMra0902814

3. Kaplan BS, Meyers KE, Schulman SL. The pathogenesis and treatment of hemolytic uremic syndrome. J Am Soc Nephrol. (1998) 9:1126-33.

4. Goodship TH, Cook HT, Fakhouri F, Fervenza FC, Fremeaux-Bacchi V, Kavanagh D, et al. Atypical hemolytic uremic syndrome and C3 glomerulopathy: conclusions from a "Kidney Disease: Improving Global Outcomes” (KDIGO) controversies conference. Kidney Int. (2017) 91:53951. doi: 10.1016/j.kint.2016.10.005

5. Huemer M, Scholl-Burgi S, Hadaya K, Kern I, Beer R, Seppi K, et al. Three new cases of late-onset cblC defect and review of the literature illustrating when to consider inborn errors of metabolism beyond infancy. Orphanet J Rare Dis. (2014) 9:161. doi: 10.1186/s13023-014-0161-1

6. Lemaire M, Fremeaux-Bacchi V, Schaefer F, Choi M, Tang WH, Le Quintrec $\mathrm{M}$, et al. Recessive mutations in DGKE cause atypical hemolytic-uremic syndrome. Nat Genet. (2013) 45:531-6. doi: 10.1038/ng.2590

7. Mele C, Lemaire M, Iatropoulos P, Piras R, Bresin E, Bettoni S, et al. Characterization of a new DGKE intronic mutation in genetically unsolved cases of familial atypical hemolytic uremic syndrome. Clin J Am Soc Nephrol. (2015) 10:1011-9. doi: 10.2215/CJN.08520814

8. George JN, Nester CM. Syndromes of thrombotic microangiopathy. N Engl J Med. (2014) 371:654-66. doi: 10.1056/NEJMra1312353

9. Bu F, Borsa N, Gianluigi A, Smith RJ. Familial atypical hemolytic uremic syndrome: a review of its genetic and clinical aspects. Clin Dev Immunol. (2012) 2012:370426. doi: 10.1155/2012/370426

10. Warwicker P, Goodship TH, Donne RL, Pirson Y, Nicholls A, Ward $\mathrm{RM}$, et al. Genetic studies into inherited and sporadic hemolytic uremic syndrome. Kidney Int. (1998) 53:836-44. doi: 10.1111/j.1523-1755.1998. 00824.x

11. Fakhouri F, Zuber J, Fremeaux-Bacchi V, Loirat C. Haemolytic uraemic syndrome. Lancet. (2017) 390:681-96. doi: 10.1016/S0140-6736(17) 30062-4

12. Bresin E, Rurali E, Caprioli J, Sanchez-Corral P, Fremeaux-Bacchi V, Rodriguez de Cordoba S, et al. Combined complement gene mutations in atypical hemolytic uremic syndrome influence clinical phenotype. J Am Soc Nephrol. (2013) 24:475-86. doi: 10.1681/ASN.2012090884

\section{ACKNOWLEDGMENTS}

The authors thank Marilena Mister for her contribution to flow cytometry experiments, Antonio Cannata and Silvia Ferrari for biochemical evaluation of C3 and C4 in plasma/serum samples, Sara Gamba for the collection of biological samples, Mrs. Kerstin Mierke for editing the manuscript, and Manuela Passera for secretarial assistance. Finally, we thank the clinicians and patients for their membership in and support of the International Registry of HUS/TTP.

\section{SUPPLEMENTARY MATERIAL}

The Supplementary Material for this article can be found online at: https://www.frontiersin.org/articles/10.3389/fmed. 2020.579418/full\#supplementary-material

Supplementary Figure 1 | Gating strategy used to evaluate CD46 surface expression on lymphocytes by flow cytometry. Fresh or thawed PBMCs were labeled with anti-human CD3 antibody and with antibody anti-human CD46 FITC recognizing SCR1 epitope (A) or with antibody anti-human CD46 FITC recognizing SCR4 epitope (B).

13. Valoti E, Alberti $M$, Iatropoulos $P$, Piras $R$, Mele $C$, Breno $M$, et al. Rare functional variants in complement genes and antiFH autoantibodies-Associated aHUS. Front Immunol. (2019) 10:853. doi: 10.3389/fimmu.2019.00853

14. Noris M, Caprioli J, Bresin E, Mossali C, Pianetti G, Gamba S, et al. Relative role of genetic complement abnormalities in sporadic and familial aHUS and their impact on clinical phenotype. Clin J Am Soc Nephrol. (2010) 5:1844-59. doi: 10.2215/CJN.02210310

15. Rodriguez de Cordoba S, Hidalgo MS, Pinto S, Tortajada A. Genetics of atypical hemolytic uremic syndrome (aHUS). Semin Thromb Hemost. (2014) 40:422-30. doi: 10.1055/s-0034-1375296

16. Arjona E, Huerta A, Goicoechea de Jorge E, Rodriguez de Cordoba S. The familial risk of developing atypical hemolytic uremic syndrome. Blood. (2020) 136:1558-61. doi: 10.1182/blood.2020006931

17. Noris M, Brioschi S, Caprioli J, Todeschini M, Bresin E, Porrati F, et al. Familial haemolytic uraemic syndrome and an MCP mutation. Lancet. (2003) 362:1542-7. doi: 10.1016/S0140-6736(03)14742-3

18. Richards A, Kathryn Liszewski M, Kavanagh D, Fang CJ, Moulton E, Fremeaux-Bacchi V, et al. Implications of the initial mutations in membrane cofactor protein (MCP; CD46) leading to atypical hemolytic uremic syndrome. Mol Immunol. (2007) 44:111-22. doi: 10.1016/j.molimm.2006.07.004

19. Nangaku M. Complement regulatory proteins in glomerular diseases. Kidney Int. (1998) 54:1419-28. doi: 10.1046/j.1523-1755.1998.00130.x

20. Schaefer F, Ardissino G, Ariceta G, Fakhouri F, Scully M, Isbel N, et al. Clinical and genetic predictors of atypical hemolytic uremic syndrome phenotype and outcome. Kidney Int. (2018) 94:408-18. doi: 10.1016/j.kint.2018.02.029

21. Osborne AJ, Breno M, Borsa NG, Bu F, Fremeaux-Bacchi V, Gale DP, et al. Statistical validation of rare complement variants provides insights into the molecular basis of atypical hemolytic uremic syndrome and C3 glomerulopathy. J Immunol. (2018) 200:2464-78. doi: 10.4049/jimmunol.1701695

22. Bu F, Maga T, Meyer NC, Wang K, Thomas CP, Nester CM, et al. Comprehensive genetic analysis of complement and coagulation genes in atypical hemolytic uremic syndrome. J Am Soc Nephrol. (2014) 25:5564. doi: 10.1681/ASN.2013050453

23. Caprioli J, Noris M, Brioschi S, Pianetti G, Castelletti F, Bettinaglio P, et al. Genetics of HUS: the impact of MCP, CFH, and IF mutations on clinical presentation, response to treatment, and outcome. Blood. (2006) 108:126779. doi: 10.1182/blood-2005-10-007252 
24. Fremeaux-Bacchi V, Moulton EA, Kavanagh D, Dragon-Durey MA, Blouin J, Caudy A, et al. Genetic and functional analyses of membrane cofactor protein (CD46) mutations in atypical hemolytic uremic syndrome. J Am Soc Nephrol. (2006) 17:2017-25. doi: 10.1681/ASN.2005101051

25. Maga TK, Nishimura CJ, Weaver AE, Frees KL, Smith RJ. Mutations in alternative pathway complement proteins in American patients with atypical hemolytic uremic syndrome. Hum Mutat. (2010) 31:E144560. doi: $10.1002 /$ humu. 21256

26. Bhatia D, Khandelwal P, Sinha A, Hari P, Cheong HI, Bagga A. Incomplete penetrance of CD46 mutation causing familial atypical hemolytic uremic syndrome. Pediatr Nephrol. (2015) 30:2215-20. doi: 10.1007/s00467-015-3189-0

27. Richards S, Aziz N, Bale S, Bick D, Das S, Gastier-Foster J, et al. Standards and guidelines for the interpretation of sequence variants: a joint consensus recommendation of the American College of medical genetics and genomics and the association for molecular pathology. Genet Med. (2015) 17:40524. doi: 10.1038 /gim.2015.30

28. Abarrategui-Garrido C, Martinez-Barricarte R, Lopez-Trascasa M, de Cordoba SR, Sanchez-Corral P. Characterization of complement factor $\mathrm{H}$ related (CFHR) proteins in plasma reveals novel genetic variations of CFHR1 associated with atypical hemolytic uremic syndrome. Blood. (2009) 114:426171. doi: 10.1182/blood-2009-05-223834

29. Hsu EC, Dorig RE, Sarangi F, Marcil A, Iorio C, Richardson CD. Artificial mutations and natural variations in the CD46 molecules from human and monkey cells define regions important for measles virus binding. J Virol. (1997) 71:6144-54. doi: 10.1128/JVI.71.8.6144-6154.1997

30. Morigi M, Galbusera M, Binda E, Imberti B, Gastoldi S, Remuzzi A, et al. Verotoxin-1-induced up-regulation of adhesive molecules renders microvascular endothelial cells thrombogenic at high shear stress. Blood. (2001) 98:1828-35. doi: 10.1182/blood.V98.6.1828

31. Fang CJ, Fremeaux-Bacchi V, Liszewski MK, Pianetti G, Noris M, Goodship $\mathrm{TH}$, et al. Membrane cofactor protein mutations in atypical hemolytic uremic syndrome (aHUS), fatal Stx-HUS, C3 glomerulonephritis, and the HELLP syndrome. Blood. (2008) 111:624-32. doi: 10.1182/blood-2007-04-084533

32. Caprioli J, Castelletti F, Bucchioni S, Bettinaglio P, Bresin E, Pianetti G, et al. Complement factor $\mathrm{H}$ mutations and gene polymorphisms in haemolytic uraemic syndrome: the C-257T, the A2089G and the G2881T polymorphisms are strongly associated with the disease. Hum Mol Genet. (2003) 12:338595. doi: $10.1093 / \mathrm{hmg} / \mathrm{ddg} 363$

33. Esparza-Gordillo J, Goicoechea de Jorge E, Buil A, Carreras Berges L, LopezTrascasa M, Sanchez-Corral P, et al. Predisposition to atypical hemolytic uremic syndrome involves the concurrence of different susceptibility alleles in the regulators of complement activation gene cluster in 1q32. Hum Mol Genet. (2005) 14:703-12. doi: 10.1093/hmg/ddi066

34. Pickering MC, de Jorge EG, Martinez-Barricarte R, Recalde S, Garcia-Layana A, Rose KL, et al. Spontaneous hemolytic uremic syndrome triggered by complement factor $\mathrm{H}$ lacking surface recognition domains. J Exp Med. (2007) 204:1249-56. doi: 10.1084/jem.20070301

35. Fremeaux-Bacchi V, Kemp EJ, Goodship JA, Dragon-Durey MA, Strain L, Loirat $\mathrm{C}$, et al. The development of atypical haemolytic-uraemic syndrome is influenced by susceptibility factors in factor $\mathrm{H}$ and membrane cofactor protein: evidence from two independent cohorts. J Med Genet. (2005) 42:8526. doi: 10.1136/jmg.2005.030783

36. de Cordoba SR, de Jorge EG. Translational mini-review series on complement factor $\mathrm{H}$ : genetics and disease associations of human complement factor $\mathrm{H}$. Clin Exp Immunol. (2008) 151:1-13. doi: 10.1111/j.1365-2249.2007.03552.x

37. Noris M, Galbusera M, Gastoldi S, Macor P, Banterla F, Bresin E, et al. Dynamics of complement activation in aHUS and how to monitor eculizumab therapy. Blood. (2014) 124:1715-26. doi: 10.1182/blood-2014-02558296

38. Galbusera M, Noris M, Gastoldi S, Bresin E, Mele C, Breno M, et al. An ex vivo test of complement activation on endothelium for individualized eculizumab therapy in hemolytic uremic syndrome. Am J Kidney Dis. (2019) 74:56-72. doi: 10.1053/j.ajkd.2018.11.012

39. Liszewski MK, Leung M, Cui W, Subramanian VB, Parkinson J, Barlow PN, et al. Dissecting sites important for complement regulatory activity in membrane cofactor protein (MCP; CD46). J Biol Chem. (2000) 275:37692701. doi: 10.1074/jbc.M004650200

40. Liszewski MK, Atkinson JP. Complement regulator CD46: genetic variants and disease associations. Hum Genomics. (2015) 9:7. doi: 10.1186/s40246-015-0029-Z

41. Yan K, Desai K, Gullapalli L, Druyts E, Balijepalli C. Epidemiology of atypical hemolytic uremic syndrome: a systematic literature review. Clin Epidemiol. (2020) 12:295-305. doi: 10.2147/CLEP.S245642

42. Ermini L, Goodship TH, Strain L, Weale ME, Sacks SH, Cordell HJ, et al. Common genetic variants in complement genes other than CFH, CD46 and the CFHRs are not associated with aHUS. Mol Immunol. (2012) 49:6408. doi: 10.1016/j.molimm.2011.11.003

43. Couzi L, Contin-Bordes C, Marliot F, Sarrat A, Grimal P, Moreau JF, et al. Inherited deficiency of membrane cofactor protein expression and varying manifestations of recurrent atypical hemolytic uremic syndrome in a sibling pair. Am J Kidney Dis. (2008) 52:e5-9. doi: 10.1053/j.ajkd.2008.02.359

44. Jokiranta TS, Zipfel PF, Fremeaux-Bacchi V, Taylor CM, Goodship TJ, Noris M. Where next with atypical hemolytic uremic syndrome? Mol Immunol. (2007) 44:3889-900. doi: 10.1016/j.molimm.2007.06.003

45. Noone DG, Riedl M, Pluthero FG, Bowman ML, Liszewski MK, Lu L, et al. Von Willebrand factor regulates complement on endothelial cells. Kidney Int. (2016) 90:123-34. doi: 10.1016/j.kint.2016.03.023

46. Noris M, Mescia F, Remuzzi G. STEC-HUS, atypical HUS and TTP are all diseases of complement activation. Nat Rev Nephrol. (2012) 8:62233. doi: $10.1038 /$ nrneph.2012.195

47. Riedl M, Noone DG, Khan MA, Pluthero FG, Kahr WHA, Palaniyar N, et al. Complement activation induces neutrophil adhesion and neutrophil-platelet aggregate formation on vascular endothelial cells. Kidney Int Rep. (2017) 2:66-75. doi: 10.1016/j.ekir.2016.08.015

Conflict of Interest: MN has received honoraria from Alexion Pharmaceuticals for giving lectures and for participating in advisory boards. $\mathrm{MN}$ has received research grants from Omeros, Alnylam, and ChemoCentryx. GR has consultancy agreements with AbbVie, Alexion Pharmaceuticals, Bayer Healthcare, Reata Pharmaceuticals, Novartis Pharma, AstraZeneca, Otsuka Pharmaceutical Europe, and Concert Pharmaceuticals; for which no personal remuneration was accepted, and compensation is paid to his institution for research and educational activities.

The remaining authors declare that the research was conducted in the absence of any commercial or financial relationships that could be construed as a potential conflict of interest.

Copyright $\odot 2020$ Piras, Iatropoulos, Bresin, Todeschini, Gastoldi, Valoti, Alberti, Mele, Galbusera, Cuccarolo, Benigni, Remuzzi and Noris. This is an open-access article distributed under the terms of the Creative Commons Attribution License (CC $B Y)$. The use, distribution or reproduction in other forums is permitted, provided the original author(s) and the copyright owner(s) are credited and that the original publication in this journal is cited, in accordance with accepted academic practice. No use, distribution or reproduction is permitted which does not comply with these terms. 